\title{
"HIP" New Software: The Hydroecological Integrity Assessment Process
}

\section{Linking Streamflow and Stream Health}

Managing rivers and streams to maintain healthy aquatic ecosystems is a challenge for resource managers across the country. Demand for competing uses of water resources grows with escalating development, increasing recreational use, and the vagaries of climate and weather. For many species of concern, instream flow and associated water quality are critical for survival. Balancing ecosystem needs with proposed changes in flow regimes requires a process managers can use to determine the ecological and hydrological effects of changes in streamflow.

In response, scientists at the USGS Fort Collins Science Center (FORT) have developed the Hydroecological Integrity Assessment Process (HIP) and a suite of software tools for conducting a hydrologic classification of streams, addressing instream flow needs, and assessing past and proposed hydrologic alterations on streamflow and other ecosystem components. The HIP recognizes that streamflow is strongly related to many critical physiochemical components of rivers, such as dissolved oxygen, channel geomorphology, and habitats. Streamflow is considered a "master variable" that limits the distribution, abundance, and diversity of many aquatic plant and animal species.

The HIP is intended for use by Federal and State agencies, institutions, private firms, and nongovernmental entities that have responsibility for or interest in managing and (or) regulating streams to maintain or restore ecological integrity. In addition, the HIP can assist managers and researchers by identifying ecologically relevant, stream-class-specific hydrologic indices

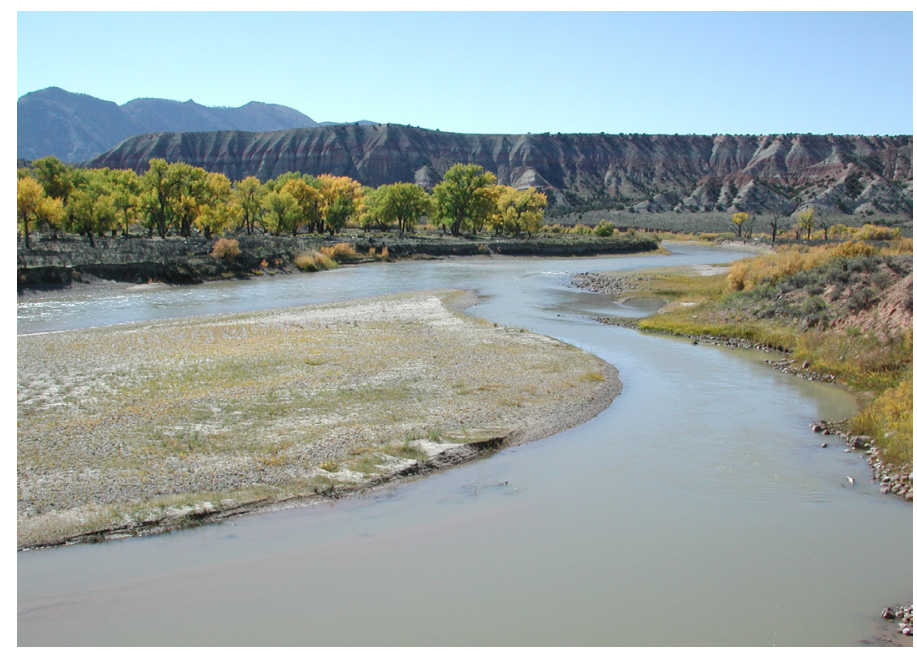

The Green River in Dinosaur National Monument, Utah. Photo by Doug Andersen/USGS.

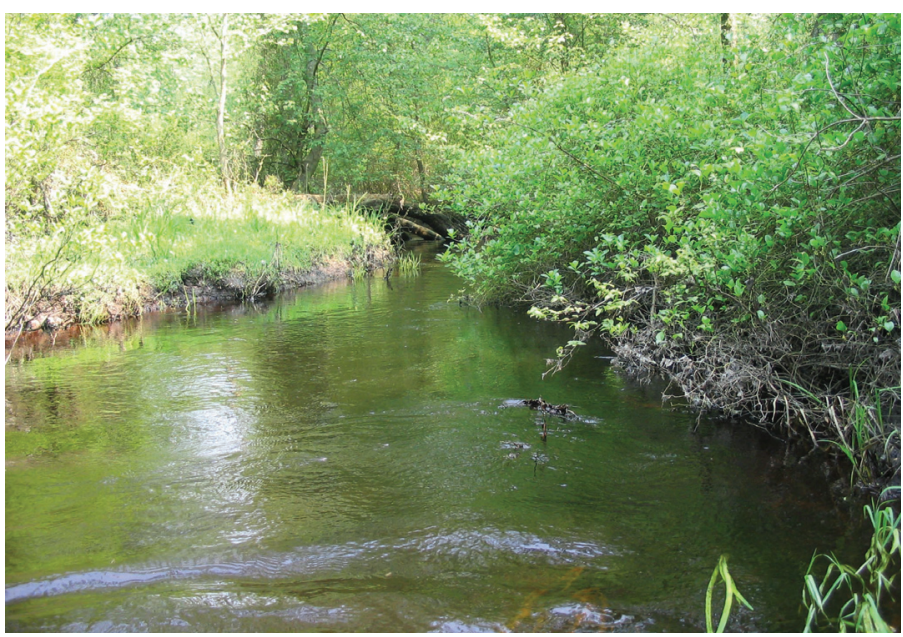

Photo courtesy of New Jersey Department of Environmental Protection.

that adequately characterize the five major components of the flow regime (magnitude, frequency, duration, timing, and rate of change) by using 10 nonredundant indices. The process is developed at a State or other large geographical area scale but applied at the stream reach level (fig. 1).

To date, the software tools have been specifically developed for the State of New Jersey and are in development for several additional States, including Missouri and Massachusetts.

\section{The "HIP" Options}

Three options are available to resource managers and scientists depending on your specific needs: (1) develop the HIP for a State or region, (2) apply the National Hydrologic Assessment Tool, or (3) apply the state-specific New Jersey HIP-derived tools.

\section{Develop the Hydroecological Integrity Assessment Process (HIP)}

If you wish to develop a HIP for your State or region, FORT scientists will work with you to classify your streams and build customized State-specific software. To learn more about the HIP, download and read the Users' Manual for the Hydrological Integrity Assessment Process Software and "Redundancy and the choice of hydrologic indices for characterizing streamflow regimes" by Olden and Poff (2003) (see Web References, next page). The introduction in the Users' Manual explains the purpose of the Hydrologic Index Tool (HIT), which calculates 171 ecologically relevant hydrologic indices using daily and peak flow records. The indices are then used for a State or regional stream classification analysis. If you're interested in developing a customized HIP, contact USGS scientist Jim Henriksen at FORT (see For More Information, next page). 


\section{Apply the National Hydrologic Assessment Tool (NATHAT)}

NATHAT is stand-alone software that requires the user to assign a stream class to a river or stream reach of interest based on a national stream classification (using six stream types), as described in "A hydrogeography of unregulated streams in the United States and an examination of scaledependence in some hydrological descriptors" (Poff, 1996). Although helpful, this national classification is less refined

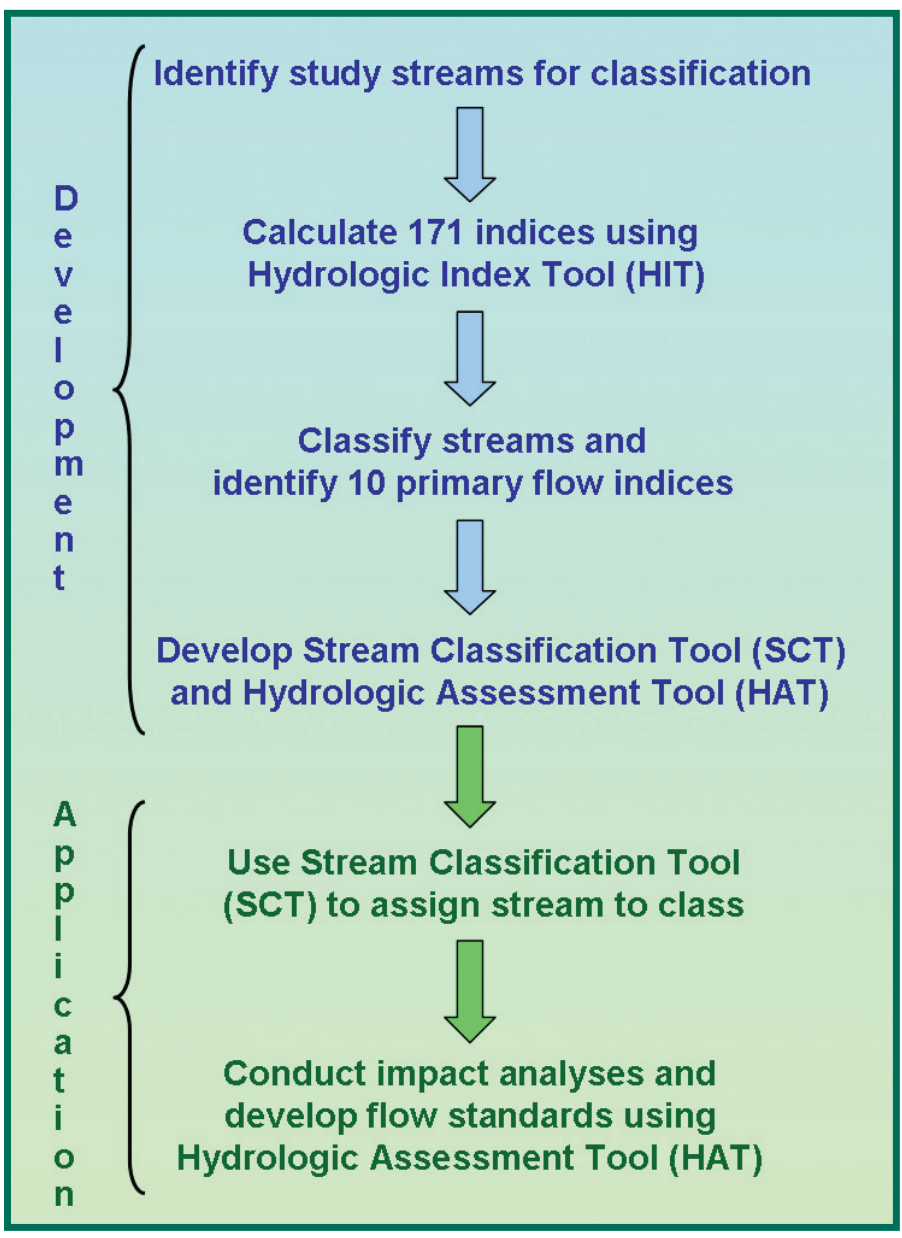

Figure 1. Steps involved in developing and applying the Hydroecological Integrity Assessment Process (HIP). than classifications developed through the HIP at the State or regional level. For example, the national classification identified only two stream types in New Jersey, but the New Jersey-specific stream classification identified four stream types. Federal agencies involved in water management issues (such as the U.S. Fish and Wildlife Service, the Bureau of Reclamation, and the Army Corps of Engineers) will find the National Hydrologic Assessment Tool of particular value for quantifying the extent of hydrologic alteration.

\section{Apply the New Jersey Tools (NJHAT and NJSCT)}

Managers in the State of New Jersey can apply the State-specific software tools using the New Jersey Hydrologic Assessment Tool (NJHAT) and the New Jersey Stream Classification Tool (NJSCT) for unclassified stream and river reaches. Also, managers considering development of a customized HIP for their State or area of interest can compare the benefits of the customized NJHAT with NATHAT.

\section{For More Information}

To discuss development of a HIP for your State or geographic area of interest, or for more information about the process and software tools, contact:
Brian Cade
U.S. Geological Survey
Fort Collins Science Center
2150 Centre Ave., Bldg. C
Fort Collins, CO 80526-8118
Tel: 970.226 .9326
Fax: 970.226.9230
E-mail: cadeb@usgs.gov

\section{Web Resources}

- Users' Manual for the Hydrological Integrity Assessment Process Software (Open-File Report 2006-1093). Available at http://www.fort.usgs.gov/products/publications/21598/21598.asp

- National Hydrologic Assessment Tool (NATHAT). Available at http://www.fort.usgs.gov/Products/Software/NATHAT/

- New Jersey Hydrologic Assessment Tool (includes the NJSCT). Available at http://www.fort.usgs.gov/Products/Software/NJHAT/

- Poff, N.L. 1996. A hydrogeography of unregulated streams in the United States and an examination of scale-depen dence in some hydrological descriptors. Freshwater Biology 36:71-91. Available at http://rydberg.biology.colostate.edu/poffpubs/Poff1996(FWB_hydrogeogr).pdf

- Olden, J.D., and N.L. Poff. 2003. Redundancy and the choice of hydrologic indices for characterizing streamflow regimes. River Research and Applications 19:101-121. Available at http://rydberg.biology.colostate.edu/poffpubs/Olden2003(RRM_Hydrol_Index).pdf 